\title{
Customized Human Skin Simulants
}

\author{
Arnab Chanda ${ }^{1}$ \\ Department of Aerospace Engineering and Mechanics, \\ University of Alabama, Tuscaloosa, 35487, USA \\ Zachary Flynn ${ }^{2}$ \\ Department of Mechanical Engineering \\ University of Alabama, Tuscaloosa, 35487, USA \\ and \\ Vinu Unnikrishnan ${ }^{3}$ \\ Department of Aerospace Engineering and Mechanics, \\ University of Alabama, Tuscaloosa, 35487, USA
}

\begin{abstract}
A simulant which precisely mimics the linear and non-linear mechanical properties of "the human skin" would be indispensable for assessment of load responses (and discomfort) produced by wearable technologies in the aerospace industry, be it an electronic sensor or a full body suit. In the current work, for the first time, a methodology has been developed to fabricate customized human skin simulants for any person and part of the body. The material comprises of four parts of silicone, which when mixed in different ratios, produces skin simulants with different stiffness properties. Extensive mechanical tests have been performed on different variants of the human skin simulants, and their stress versus strain responses have been matched with actual human skin test data from the literature. Also, the fracture properties of the simulants have been found to be in close range of the actual human skin. Additionally, non-linear hyperelastic constitutive models were used to fully characterize the mechanical behavior of the skin simulant variants. Mechanical tests on freshly excised porcine skin were conducted to validate our test results. To date, such accurate skin simulants has not been developed anywhere to the best of our knowledge. The material is cheap $(\$ 15 / \mathrm{lb})$, has no biosafety or handling issues (unlike cadavers, cowhides or porcine skin), and castable to any shape or size. Besides testing, the skin simulants could also be used to develop liners for the wearable technologies, which are just like the skin of the person wearing it, thus reducing discomfort due to material mismatch and friction. Additionally, the skin simulants find applications in the area of manufacturing of prosthetics (liners) and orthotics, military grade armors and personal protection equipment (PPE), and testing of non-lethal and less-lethal ballistics.
\end{abstract}

\section{Introduction}

The skin is the outer protective covering of the human body with an average total area close to 20 square feets, and composed of three layers namely the epidermis (outermost soft layer), the dermis (middle layer) and hypodermis

\footnotetext{
${ }^{1}$ Masters Student, Department of Aerospace Engineering and Mechanics, University of Alabama, Tuscaloosa, 35487, USA

${ }^{2}$ Former Undergraduate Student, Department of Mechanical Engineering, University of Alabama, Tuscaloosa, 35487, USA

${ }^{3}$ Assistant Professor, Department of Aerospace Engineering and Mechanics, University of Alabama, Tuscaloosa, 35487, USA
} 
(inner most layer made of strong connective tissues), with an average thickness of 1-4 $\mathrm{mm}^{3}$ as shown in Fig. 1. The skin is the first point of contact for any external load with the human body, and also the first barrier against any physical injury. Since early 1980's, there have been several attempts to develop artificial skin replacements for severe burn injuries ${ }^{4}$. The main focus has been on recreating the biocompatibility and mechanical properties of the natural skin. In literature, the mechanical properties of human skin ${ }^{5-9}$ has been studied extensively through uniaxial ${ }^{10}$, biaxial ${ }^{11-15}$, multiaxial ${ }^{16}$ and indentation tests ${ }^{17-20}$, under both static and dynamic loading ${ }^{21,22}$ conditions, and also using imaging techniques ${ }^{18,23,24}$. It has been observed that mechanically, skin behaves like a non-linear hyperelastic material which stiffens with the increase in applied load. Several phenomenological material models of the skin ${ }^{25}$ have been developed in the past for burnt skin replacements ${ }^{4}$ and also for surgical needle insertion simulations ${ }^{26}$, to study skin optical properties 27,28 , perfusion ${ }^{29}$, sports

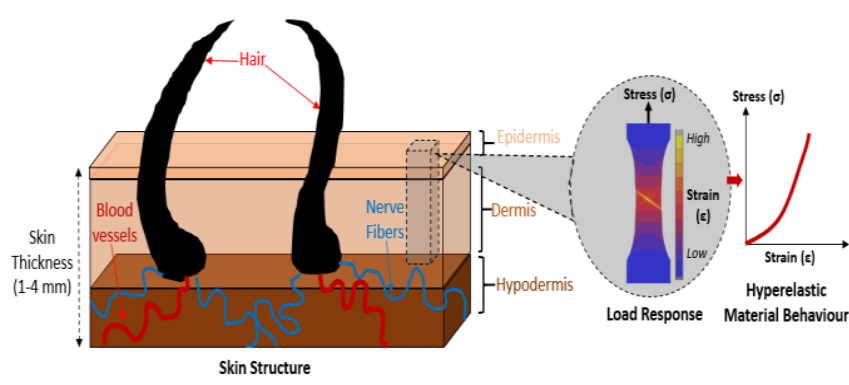

Figure 1. Skin structure and a typical skin specimen load response characteristics plot. injuries 30,31 , and test for the penetration resistance to ballistics ${ }^{32-35}$. However surprisingly, the realistic non-linear hyperelastic material properties of the human skin has never been simulated, which we propose would be indispensable for assessment of load responses (and discomfort) produced by wearable technologies in the aerospace industry such as an electronic sensor ${ }^{36}$ or a full body space suit ${ }^{37}$. Also, fabrication of such customized human skin simulants would be useful for biomechanical testing applications such as estimating the load response of cosmetic implants and biomechanical study of skin injuries. Additionally, an ongoing goal in the ballistic community has been to develop less-lethal munitions ${ }^{38}$, which is aimed at detering individuals without causing fatal injuries. A simulant with realistic mechanical properties of the human skin is therefore imperetive to test the load response of such munitions prior to their deployment in the field.

Based on the concept of silicone based breast implants ${ }^{39}$, and extensive mechanical testing data on the human skin available in the literature ${ }^{2,40-43}$, a novel silicone based human skin simulant, which mechanically behaves like the natural human skin, has been developed ${ }^{1}$. The manufacturing and fabrication steps involved are discussed in detail in section II. Section III will present the experimental results on the mechanical testing on the human skin simulant, comparison with a comprehensive literature data on mechanical testing of the human skin, mechanical characterization, and also the mechanical testing results on pig skin which was performed to validate our material model for the human skin simulant. Section IV will conclude with a summary of the novel material model system and also highlight some immediate and future application areas.

\section{Materials and Methods}

\section{A. Fabrication of Human Skin Simulants}

Silicone based materials are characterized using the Shore (Durometer) hardness scale, defined as per the American Society for Testing and Materials (ATSM) D2240 testing standard. A two-part extremely soft silicone material with shore hardness of 10 was combined with a harder two-part silicone material with shore hardness 30 to fabricate the novel human skin simulant material ${ }^{1}$. A mold was

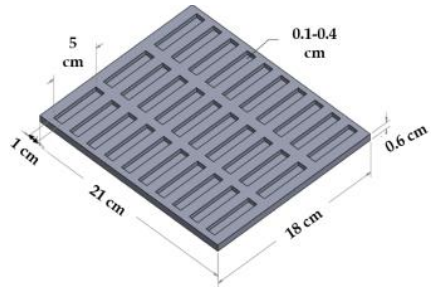

(A)

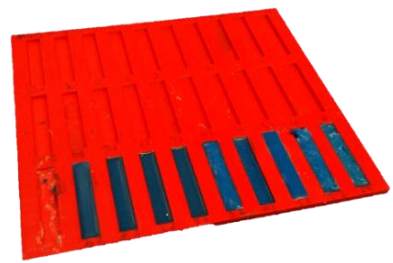

(B)

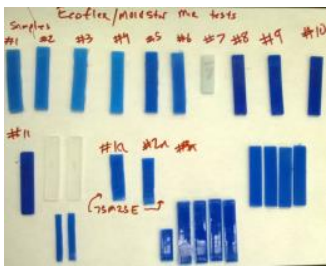

(C)

Figure 2. A) Mold design for test coupons in Solidworks, B) 3D printed mold for test coupons, C) Some specimens with different sizes and colour variation (implying different mix ratios). 
depth, 10 coupons with $3 \mathrm{~mm}$ depth, 5 coupons with $1 \mathrm{~mm}$ depth and 5 coupons with $4 \mathrm{~mm}$ depth). The overall dimension of the mold was $21 \mathrm{~cm} \times 18 \mathrm{~cm} \times 1 \mathrm{~cm}$. This mold design was exported as an steriolithographic (STL) file and sent for 3D printing at the University of Alabama 3D printing lab. The 3D printer used was Stratasys Dimension SST 1200es and the material used for fabricating the mold was Acrylonitrile butadiene styrene (ABS), a very popular material used in the 3D printing industry which provides a good surface finish and high strength. The 3D printed mold is shown in Fig. 2 B.

To start with the fabrication of silicone test coupons, multiple test specimens (55 specimens) of similar dimension $(49 \mathrm{~mm}<$ Length $<50 \mathrm{~mm}, 9 \mathrm{~mm}<$ Width $<11 \mathrm{~mm}$ and $1 \mathrm{~mm}<$ Thickness $<4 \mathrm{~mm})$ were prepared with abstract weight percentages of the four-part silicone, mechanically tested on the MTS universal testing machine, and the load response plots were compared with the most comprehensive literature data ${ }^{2,30,31}$, to identify weight percentage ranges of the four parts, which will best result in developing test specimens with mechanical properties close to that of natural human skin. The best results were obtained by mixing part A (25-45 wt. \% silicone with shore hardness $30)$, part B (25-45 wt. \% silicone with shore hardness 30), part A (5-25 wt. \% silicone with shore hardness 10) and part B (5-25 wt. \% silicone with shore hardness 10$){ }^{1}$ with a mean curing time of 6.5 hours. The next step was to determine a precise mix ratio which can be used to develop a control specimen for testing. For this purpose, a test specimen, named "90-10", which is composed of precisely measured (using experimental measuring cups and Ohaus Adventurer Pro precesion weight measuring device) $45 \mathrm{wt}$ \% part A silicone with shore hardness 30, $45 \mathrm{wt}$. \% part B silicone with shore hardness 30, 5 wt. \% part A silicone with shore hardness 10, 5 wt. \% part B silicone with shore hardness 10 , was fabricated. This 90-10 specimen was further used for the comparison study with the mechanical properties of the natural human skin.

\section{B. Mechanical Testing}

Several considerations need to be taken while testing soft materials such as silicone rubber and the skin ${ }^{44}$. First, soft materials slip very easily, thereby special grips coated with any material which provides high friction against slipping needs to be used. Second, strain rate significantly affects the load response of soft materials ${ }^{45}$ and this phenomenon has been observed with the skin too ${ }^{46}$, which necessitates the use of a specific strain rate, so that results can be precisely compared with literature. Third, the shape and size of the specimen may affect the test results ${ }^{47}$. All these issues have been factored in our experimental framework. Special grips have been used for specimen gripping, and a specific specimen size and strain rate have been used throughout for experiments. Additionally a very small initial load $(<0.1 \mathrm{~N})$ is applied on each test specimen to ensure there is no slack in the specimen to start with. A constant strain rate of $0.4 \mathrm{~s}^{-1}$ and specimen size of $35 \mathrm{~mm} \times 10 \mathrm{~mm} \times 2.5 \mathrm{~mm}$ (after clamping) has been selected for all the uniaxial tests on silicone based material, based on literature on uniaxial tests on human skin ${ }^{2,30,31,43}$. For each of the tests (see Fig. $3)$, the Load $(\mathrm{N})$ versus extension $(\mathrm{mm})$ graphs are plotted.

Edible grade fresh pig skin sample (Fig. 4) was obtained from the supermarket in Tuscaloosa, Alabama and tested in the Advanced Compuational and Experiemntal Mechanics Laboratory (ACEML), University of Alabama (UA) which is Biosafety level 2 facility. All the hair on the skin was carefully trimmed off and the skin sample was hydrated in a water bath at room temperature $\left(75^{0} \mathrm{~F}\right)$ for

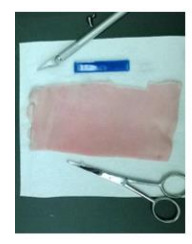

(A)

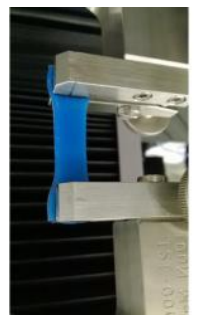

Figure 3. Uniaxial test on a silicone specimen captured in the beginning and during a test.

2 hours. The hypodermis was carefully removed through blunt dissection, ensuring that no damage was caused to the dermis. The average thickness of the skin was measured as $2 \pm 0.5 \mathrm{~mm}$ and test samples of width $(9 \mathrm{~mm}<W<11 \mathrm{~mm})$ and length $(33 \mathrm{~mm}<L<35 \mathrm{~mm})$ were extracted (10 samples). Each test specimen was positioned, dermis side down on an aluminum foil to prevent skin curling, and subsequently clamped in between the grips of the universal testing machine, and the foil was removed carefully. All samples were uniaxially tested at constant strain rate of $0.4 \mathrm{~s}^{-1}$ to obtain load-extension plots. 
For post-processing of the raw load-extension curves obtained from the universal testing machine, a well defined protocol was followed comprising of seven major steps. First, any part of the plots which show negative load values were trimmed off (which may arise from the specimen being slack initially). Second, any part of the plots after the yield point was trimmed off, as they are insignificant for our analysis. Third, the calibration errors in the MTS machine were tracked and the graphs were shifted accordingly. Fourth, the engineering stress versus engineering strain plots were replotted as true stress versus true strain plots which are obtained using Eq. (1) and Eq. (2). Fifth, highly accurate 5th degree polynomial trend lines are fit to each of the plots with $\mathbf{R}^{2}$ (coefficient of determination) values between 0.99 and 1. Sixth, all the plot strain (X axis) steps and ranges are standardized $(1<\varepsilon$ true $<2$ at 0.01 increment steps), and the respective stress values are calculated using the trend line equations obtained in step 5, and re-plotted. Seventh, each stress versus strain plot is converted to stress versus stretch ( $\lambda$ ) plots using the Eq. (3). Subsequently, the stress versus stretch curves are fit into hyperelastic material models (discussed in the following section).

$$
\begin{gathered}
\sigma_{\text {true }}=\sigma_{\text {eng }}\left(1+\varepsilon_{\text {eng }}\right) \\
\varepsilon_{\text {true }}=\ln \left(1+\varepsilon_{\text {eng }}\right) \\
\lambda=1+\varepsilon
\end{gathered}
$$

\section{Material Modeling}

Soft tissues are in general non-linear materials which stiffen at high strains (or stretches). At low and high stretch values, a small section of the plots could be considered linear and a respective low stretch and a high stretch modulus of elasticity can be defined. A high stretch modulus of elasticity refers to the final elasticity modulus or slope of the stress versus stretch plot of a non-linear material before rupture. The way to measure this is to draw a line starting at the point of rupture and tangent to the stress versus stretch plot, and numerically estimate its slope. A low stretch modulus of elasticity refers to the initial elasticity modulus or slope of the stress versus stretch plot of a non-linear material approximated at low stretch values. To measure this, a line is drawn starting at the origin and tangent to the stress versus stretch plot, and its slope is numerically estimated.

Precise prediction of the non-linear mechanical behavior of a soft tissue is carried out using hyperelastic constitutive curve fit models such as Mooney-Rivlin, Yeoh, Ogden, and Veronda-Westmann ${ }^{44}$. Hyperelastic curve fit models are based on the definition of the strain-energy function (denoted as $\boldsymbol{\Psi}$ ), which further depends on the type of material ${ }^{48,49}$. Any hyperelastic model is dependent on either the principal stretches $\left(\lambda_{1}, \lambda_{2}\right.$ and $\left.\lambda_{3}\right)$ or the Cauchy-Green tensor invariants $\left(I_{1}, I_{2}\right.$ and $I_{3}$, which are also functions of the principal stretches) ${ }^{44}$ as shown in Eq. (4-7). In this paper, the Veronda-Westmann's hyperelastic model have been used to characterize the non-linear mechanical behavior of the silicone based human skin simulant mainly because this model have been used in literature to successfully characterize human skin ${ }^{40-42}$, and thus would be good for comparing our results. The strain energy functions of the Veronda-Westmann's model is shown in Eq. (8).

$$
\begin{gathered}
\psi=\psi\left(I_{1}, I_{2}, I_{3}\right) \\
I_{1}=\sum_{i=1}^{3} \lambda_{i}^{2} \\
I_{2}=\sum_{i, j=1}^{3} \lambda_{i}^{2} \lambda_{j}^{2} \\
I_{3}=\prod_{i=1}^{3} \lambda_{i}^{2} \\
\psi_{\text {Veronda-Westmann }}=c_{1}\left[e^{c_{2}\left(I_{1}-3\right)}-1\right]-\frac{c_{1} c_{2}}{2}\left(I_{2}-3\right)
\end{gathered}
$$

Though mechanical tests on any specimen and following the procedure outlined in the literature by Martins et al. ${ }^{44}$, the principal Cauchy stress is expressed in terms of the stretch and the strain energy function using Eq. (9). Using the strain energy Eq. (8) and Eq. (9), the non-linear stress versus strain behavior of the specimen can be predicted using Eq. (10) for uniaxial tests. 


$$
\begin{gathered}
\sigma_{1}=\lambda_{1} \frac{\partial \psi}{\partial \lambda_{1}}-\lambda_{3} \frac{\partial \psi}{\partial \lambda_{3}}, \sigma_{2}=\sigma_{3}=0 \\
\sigma_{\text {Veronda-Westmann }}=2\left(\lambda_{i}^{2}-\frac{1}{\lambda_{i}}\right) c_{1} c_{2}\left(e^{c_{2}\left(I_{1}-3\right)}-\frac{1}{2 \lambda_{i}}\right), i=1
\end{gathered}
$$

True stress versus true stretch data obtained from mechanical tests were fit into Eq. (10) and the value of the material constants (such as $c_{1}, c_{2}, c_{3}$ etc.) were determined. To evaluate the accuracy of the hyperelastic model chosen in predicting the skin material behavior, an $\mathbf{R}^{\mathbf{2}}$ correlation value calculation was performed, where $\mathbf{R}^{\mathbf{2}}$ can have a value from 0 through 1,1 representing the best fit and 0 representing worst fit.

\section{Results and Discussions}

\section{A. Mechanical Tests to Develop the Human Skin Simulant}

The first batch of mechanical tests were perfomed on silicone specimens made out of mixing of abstract percentages of the fourpart silicone material, at a strain rate of $0.4 \mathrm{~s}^{-1}$ calculated using Eq. (11) and consistent with uniaxial tests on human skin in the literature ${ }^{2}$. Fig. 5 captures 23 test results out of the 55 specimens tested ${ }^{1}$ to identify a stress versus stretch range in which the mechanical properties of the human skin lie ${ }^{2,30,31}$. The four-part mix ratio corresponding to the silicone test coupons exhibiting stress versus stretch ranges in the stress versus stretch regime of the human skin $2,30,31$ was found to be part A $(25-45$ wt. \% silicone with shore hardness 30), part B (25-

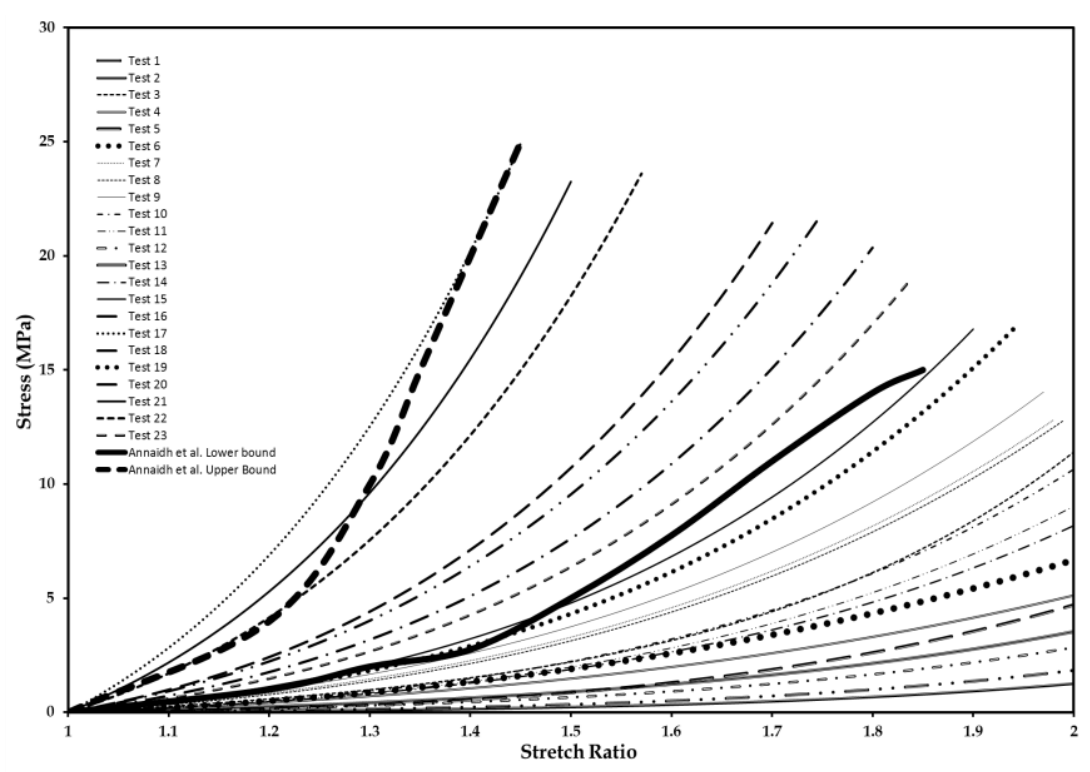

Figure 5. Stress versus stretch plots of 23 out of the 55 silicone specimens tested to fabricate the human skin simulant ${ }^{1}$, with the lower and upper bounds of actual human skin test data from Annaidh et al. ${ }^{2}$. 45 wt. \% silicone with shore hardness 30), part A (5-25 wt. \% silicone with shore hardness 10) and part B (5-25 wt. \% silicone with shore hardness 10), after repeated testing ${ }^{1}$ (see Fig. 5).

$$
\text { StrainRate }\left(\mathrm{s}^{-1}\right)=\frac{\text { Velocity of Crosshead }(\mathrm{mm} / \mathrm{min})}{60 \times \text { Length of Specimen }(\mathrm{mm})}
$$

For each test, the modulus of elasticity at low and high stretches were estimated. The low stretch and high stretch modulus of elasticity for the tests 1 through 23 were found to be in the range of 2-8 MPa and 6-90 MPa respectively 1 .

Excellent skin simulants with stress versus stretch responses lying within the bounds of natural human skin 2 were identified (see Fig. 5). The low stretch and high stretch modulus for excellent skin simulants were found to be in the range of 4-8 $\mathrm{MPa}$ and $34-90 \mathrm{MPa}$ (similar to that of natural human skin ${ }^{2}$ ) respectively ${ }^{1}$. 
A silicone test coupon made of $45 \mathrm{wt}$. $\%$ part A silicone with shore hardness 30, 45 wt. \% part B silicone with shore hardness 30, 5 wt. \% part A silicone with shore hardness 10,5 wt. \% part B silicone with shore hardness 10 , named as the " 90 10 specimen" was chosen ${ }^{1}$ for our specific comparison study with respect to the elasticity modulus, ultimate tensile stress (or fracture strength), and hyperelastic material modeling. Fig. 6 shows the results of the repeatibility tests (36 tests performed) on this silicone specimen, which lies in the stress versus stretch regime of the human skin $2,30,31$. To the best of our knowledge, this is the first time, a human skin simulant has been developed with the non-linear material behavour lying between the upper and lower bounds of the stress versus stretch regime of the natural human skin [39].

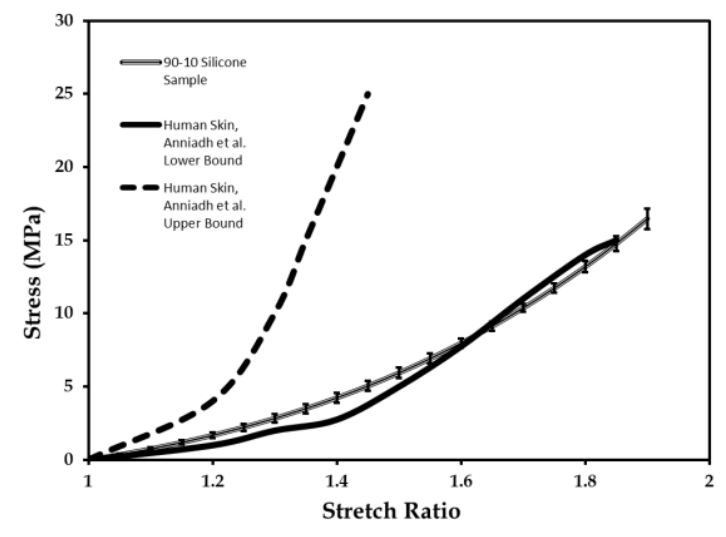

Figure 6. Stress versus stretch plot of 90-10 silicone specimen under 36 times repeatability tests, with the lower and upper bounds of actual human skin test data from Annaidh et al. ${ }^{2}$.

\section{B. Comparison of Mechanical Behavior of the Skin Simulant and Human Skin}

The novelty of the human skin simulant discussed in this article lies in the degree of precision with which it mimicks the mechanical behavour of the human skin. The non-linear stress versus stretch response, elasticity modulus (at high and low stretches), and the ultimate tensile stress of the 90-10 silicone specimen made of $45 \mathrm{wt}$. $\%$ part A silicone with shore hardness 30, 45 wt. \% part B silicone with shore hardness 30 , 5 wt. \% part A silicone with shore hardness $10,5 \mathrm{wt}$. $\%$ part B silicone with shore hardness 10 , was compared with the most comprehensive literature on mechanical properties of the human skin 2, 30, 31, 43, and validated using mechanical testing data on pig skin ${ }^{1}$.

From the stress versus stretch plot of the selected "90-10" test specimen, the mean elasticity modulus was estimated both at low and high stretch ratios from portions of the plot which are

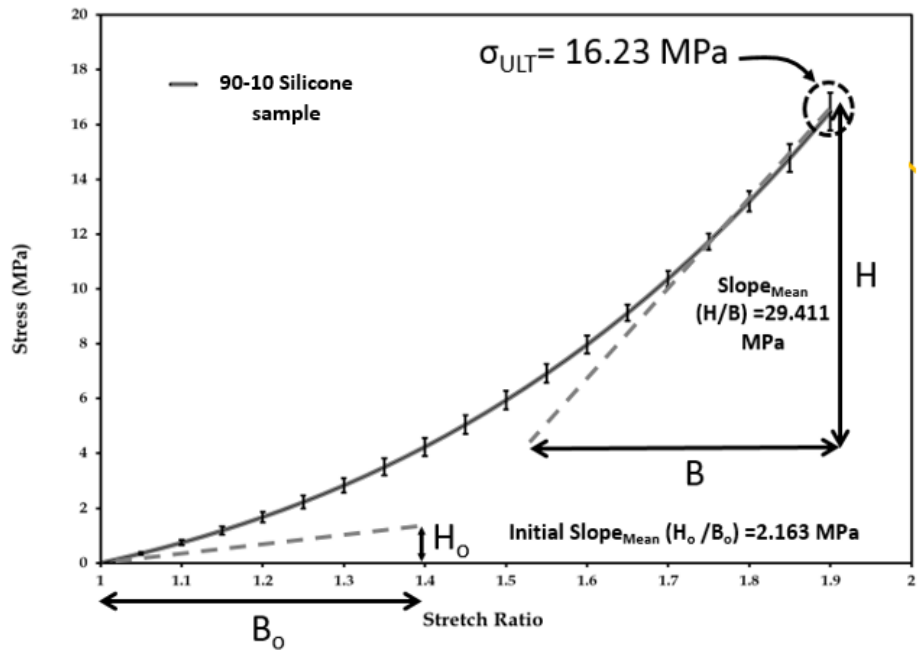

Figure 7. Estimation of elasticity modulus of the 90-10 skin simulant at high and low stretch ratios, and specimen fracture at ultimate tensile stress. linear, similar to Annaidh et al. ${ }^{2}$.

The elasticity modulus values were calculated as shown in Fig. 7 (through estimation of the slope of the stress versus stretch plot). Table 1 presents the result of the elasticity modulus at low stretch and high stretch ratios for the 36 "90-10" specimens tested for repeatibility. Also, the ultimate tensile strength (mean value shown in Fig. 7) at which a test specimen fractures (shown in Fig. 7) was observed for each of the 36 repeatibility tests on the $90-10$ specimens. Table 1 presents the results of the ultimate tensile stresses observed in our experiments. Both the elasticity modulus and ultimate stress values were found to be in close range of the human skin ${ }^{2}$. It should be further noted that the silicone 90-10 material does not rupture like the human skin, but only compares well with the ultimate tensile stress of the human skin as reported in literature ${ }^{2}$. 


\section{Curve Fitting Hyperelastic Models to Experimental data}

All the 23 initial tests in Fig. 5 were curve fitted using the Veronda Westmann's non-linear hyperelastic material model (discussed in section 2.3). The curve fit parameters (such as $c_{1}$ and $c_{2}$ ) estimated with a high corellation index $\left(\mathbf{R}^{2}\right.$ value) of over 0.999 , for the 23 tests are listed in Table 2.

\section{Mechanical Tests on Pig Skin and Validation of Experimental Test Framework}

Pig skin specimens were tested and stress versus stretch curves were plotted to validate the mechanical testing framework used for the development of the novel human skin simulant. Fig. 8 shows the stress versus stretch plots of the pig skin specimens tested and also the stress versus stretch plot of the 9010 human skin simulant specimens developed using 45 wt. $\%$ part A silicone with shore hardness 30, 45 wt. \% Table 1. Comparison of Human skin and 90-10 skin simulant

\begin{tabular}{|c|c|c|c|}
\hline Test Specimen & $\begin{array}{c}\text { Elasticity } \\
\text { Modulus (E) (Low } \\
\text { Stretch Ratio) } \\
\end{array}$ & $\begin{array}{c}\text { Elasticity Modulus } \\
\text { (E) } \\
\text { (High Stretch Ratio) }\end{array}$ & $\begin{array}{c}\text { Ultimate } \\
\text { Tensile Stress } \\
\left(\sigma_{\text {ULT }}\right) \text { MPa } \\
\end{array}$ \\
\hline $\begin{array}{l}90-10 \text { Human } \\
\text { Skin Simulant }\end{array}$ & $2.163 \pm 1.196$ & $29.411 \pm 4.261$ & $16.23 \pm 1.15$ \\
\hline Human Skin $^{2}$ & $1.18 \pm 0.88$ & $83.3 \pm 34.9$ & $21.6 \pm 8.4$ \\
\hline
\end{tabular}

part B silicone with shore hardness 30,5

wt. \% part A silicone with shore hardness 10, 5 wt. \% part B silicone with shore hardness 10 . It can be clearly observed that the stress versus stretch response of the pig skin is much higher than that of the 90-10 human skin simulant for a high stress range (Fig. $8 \mathrm{~A})$. However, if the stress range is reduced, the stress versus stretch plot (Fig. 8B) conforms closely to literature findings ${ }^{45}$. Based on the high corellation of our results with the literature, it can be concluded that our mechanical testing framework for the human skin simulant is accurate and not in a completely different regime compared to the already established experimental frameworks in literature $2,30,31,43,45$.

\section{Conclusions}

In this article, the manufacturing and fabrication methodology for a four-part silicone based non-linear human skin simulant material was presented. The fabrication technique, experimental framework, comparison study with natural human skin test data from literature were discussed. Also, the human skin simulant material was characterized using hyperelastic material modeling, and our experimental test framework was validated appropriately. Mix ratios of part A (25-45 wt. \% silicone with Table 2. Veronda-Westmann's curve fit parameters for 23 tests ${ }^{1}$ in Fig. 5

\begin{tabular}{|c|c|c|}
\hline \multirow{3}{*}{ Sample } & Veronda-Westmann Hyperelastic model coefficients \\
\cline { 2 - 3 } & $\mathbf{c}_{\mathbf{1}}$ & $\mathbf{c}_{\mathbf{2}}$ \\
\hline 1 & 1.1 & 0.23 \\
\hline 2 & 1 & 0.2 \\
\hline 3 & 5.9 & 0.28 \\
\hline 4 & 3.4 & 0.25 \\
\hline 5 & 2.3 & 0.27 \\
\hline 6 & 4 & 0.26 \\
\hline 7 & 6 & 0.32 \\
\hline 8 & 5.8 & 0.3 \\
\hline 9 & 6.5 & 0.29 \\
\hline 10 & 5.4 & 0.27 \\
\hline 11 & 5.2 & 0.26 \\
\hline 12 & 1.5 & 0.25 \\
\hline 13 & 2 & 0.3 \\
\hline 14 & 5 & 0.25 \\
\hline 15 & 11.8 & 0.2 \\
\hline 16 & 16 & 0.22 \\
\hline 17 & 35 & 0.33 \\
\hline 18 & 18 & 0.23 \\
\hline 19 & 11.5 & 0.21 \\
\hline 20 & 13.7 & 0.21 \\
\hline 21 & 28 & 0.3 \\
\hline 22 & 24 & 0.28 \\
\hline 23 & 13.1 & 0.21 \\
\hline
\end{tabular}
shore hardness 30), part B (25-45 wt. $\%$ silicone with shore hardness 30 ), part A (5-25 wt. \% silicone with shore hardness 10) and part B (5-25 wt. \% silicone with shore hardness 10) were found to generate excellent human 
skin simulants. Additionally, a skin simulant variant named as the "90-10", which is composed of $45 \mathrm{wt}$. \% part A silicone with shore hardness 30,45 wt. $\%$ part B silicone with shore hardness 30, 5 wt. \% part A silicone with shore hardness 10,5 wt. $\%$ part B silicone with shore hardness 10, was further tested to compare with natural human skin. The non-linear stress versus stretch response, elasticity modulus (at high and low stretches), and the ultimate tensile stress of the "90-10" specimen was found to be within a very close range of the natural human skin. To date, such a biomechanically precise human skin simulant has not been developed anywhere to the best of our knowledge.

The biofidelic human skin simulants would be indispensable for assessment of load responses (and discomfort) produced by wearable technologies in the aerospace industry, be it an electronic sensor or a full body suit. Also, the skin simulants could be used for testing of personal protective equipment (PPE) and safety systems (such as protective armors, sport gears etc.) can be evaluated in a wide range of industries (military, automotive, biomedical, security, sports equipment etc.). Also these skin simulant material can be employed to design human torsos for testing and development of less lethal ballistic munitions in the future.

\section{References}

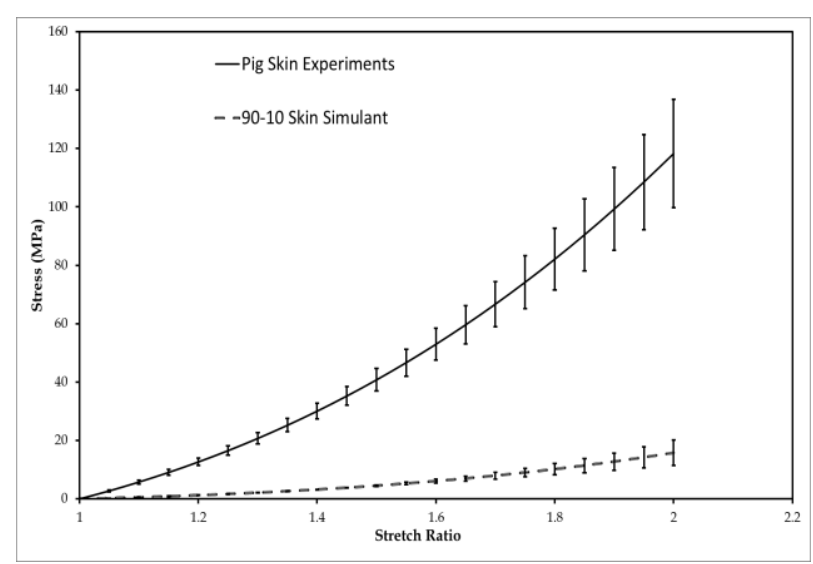

(A)

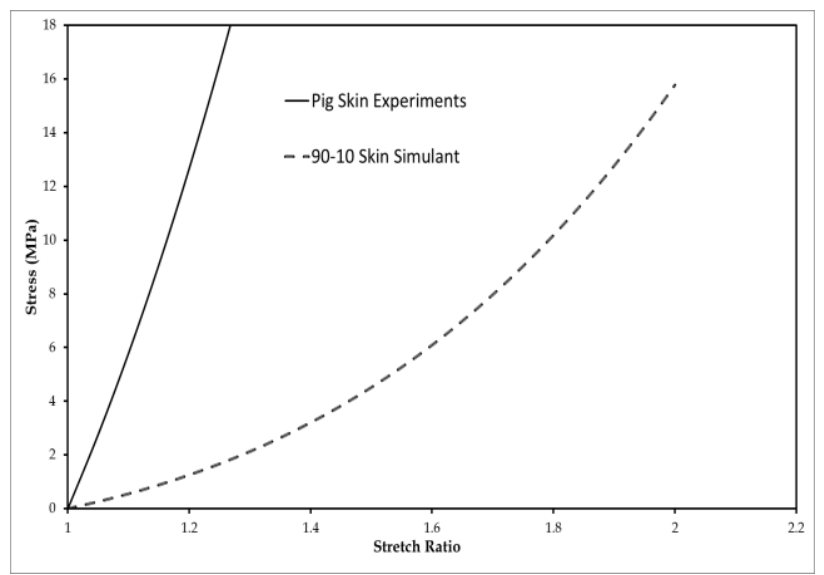

(B)

Figure 8. Stress versus stretch plots of the pig skin compared to the human skin simulant for validation of our mechanical testing framework, at A) High stress range and B) Low stress range.
Chanda, A., Unnikrishnan, Vinu, Flynn, Zachary. "Biofidelic Skin Simulant." US Provisional Patent 62/189,504, 2015. Annaidh, A. N., Bruyère, K., Destrade, M., Gilchrist, M. D., and Otténio, M. "Characterization of the anisotropic mechanical properties of excised human skin," Journal of the mechanical behavior of biomedical materials Vol. 5, No. 1, 2012, pp. 139-148.

3 McGrath, J., and Uitto, J. "Anatomy and organization of human skin," Rook's Textbook of Dermatology, Eighth Edition, 2010, pp. 1-53.

Yannas, I., and Burke, J. F. "Design of an artificial skin. I. Basic design principles," Journal of biomedical materials research Vol. 14, No. 1, 1980, pp. 65-81. 
Douven, L. F., Meijer, R., and Oomens, C. W. "Characterization of mechanical behavior of human skin in vivo," BiOS 2000 The International Symposium on Biomedical Optics. International Society for Optics and Photonics, 2000, pp. 618-629.

Hendriks, F., Brokken, D., Oomens, C., Baaijens, F., and Horsten, J. "Mechanical Properties of Different Layers of Human Skin," Internal Poster (http://yp. bmt. tue. $n l / p d f s / 249$. pdf), Department of Biomedical Engineering, Eindhoven University of Technology, 2000.

Heinrich, T., and Lunderstaedt, R. A. "Quantification of mechanical properties of human skin in vivo," International Symposium on Optical Science and Technology. International Society for Optics and Photonics, 2001, pp. 11-20. Hendriks, F. "Mechanical behaviour of human skin in vivo-a literature review," Nat. Lab. Unclassified Report 820. Philips Research Laboratories. Citeseer, 2001.

Silver, F. H., Freeman, J. W., and DeVore, D. "Viscoelastic properties of human skin and processed dermis," Skin Research and Technology Vol. 7, No. 1, 2001, pp. 18-23.

(1)

Abas, W. W., and Barbenel, J. "Uniaxial tension test of human skin in vivo," Journal of biomedical engineering Vol. 4, No. 1,1982 , pp. 65-71.

Cook, T., Alexander, H., and Cohen, M. "Experimental method for determining the 2-dimensional mechanical properties of living human skin," Medical and Biological Engineering and Computing Vol. 15, No. 4, 1977, pp. 381390.

Agache, P., Monneur, C., Leveque, J., and De Rigal, J. "Mechanical properties and Young's modulus of human skin in vivo," Archives of dermatological research Vol. 269, No. 3, 1980, pp. 221-232.

Manschot, J. F. M. "The mechanical properties of human skin in vivo," Journal of Biomechanics Vol. 19, 1985, pp. 511-515.

Manschot, J., and Brakkee, A. "The measurement and modelling of the mechanical properties of human skin in vivoII. The model," Journal of Biomechanics Vol. 19, No. 7, 1986, pp. 517-521.

Edwards, C., and Marks, R. "Evaluation of biomechanical properties of human skin," Clinics in dermatology Vol. 13, No. 4, 1995, pp. 375-380.

Kvistedal, Y., and Nielsen, P. "Investigating stress-strain properties of in-vivo human skin using multiaxial loading experiments and finite element modeling," Engineering in Medicine and Biology Society, 2004. IEMBS'04. 26th Annual International Conference of the IEEE. Vol. 2, IEEE, 2004, pp. 5096-5099.

Boyer, G., Zahouani, H., Le Bot, A., and Laquieze, L. "In vivo characterization of viscoelastic properties of human skin using dynamic micro-indentation," Engineering in Medicine and Biology Society, 2007. EMBS 2007. 29th Annual International Conference of the IEEE. IEEE, 2007, pp. 4584-4587.

Tran, H., Charleux, F., Rachik, M., Ehrlacher, A., and Ho Ba Tho, M. "In vivo characterization of the mechanical properties of human skin derived from MRI and indentation techniques," Computer methods in biomechanics and biomedical engineering Vol. 10, No. 6, 2007, pp. 401-407.

Delalleau, A., Josse, G., Lagarde, J. M., Zahouani, H., and Bergheau, J. M. "A nonlinear elastic behavior to identify the mechanical parameters of human skin in vivo," Skin Research and Technology Vol. 14, No. 2, 2008, pp. 152-164.

Pailler-Mattei, C., Bec, S., and Zahouani, H. "In vivo measurements of the elastic mechanical properties of human skin by indentation tests," Medical engineering \& physics Vol. 30, No. 5, 2008, pp. 599-606.

Finlay, B. "Dynamic mechanical testing of human skin 'in vivo'," Journal of biomechanics Vol. 3, No. 6, 1970, pp. 557-568.

Potts, R. O., Chrisman, D. A., and Buras, E. M. "The dynamic mechanical properties of human skin in vivo," Journal of biomechanics Vol. 16, No. 6, 1983, pp. 365-372.

Evans, S. L., and Holt, C. A. "Measuring the mechanical properties of human skin in vivo using digital image correlation and finite element modelling," The Journal of Strain Analysis for Engineering Design Vol. 44, No. 5, 2009, pp. 337-345.

Kearney, S. P., Dai, Z., and Royston, T. J. "Wideband optical elastography of in vivo human skin using geometrically focused surface waves," SPIE BiOS. International Society for Optics and Photonics, 2014, pp. 89460H-89460H-12. 
Payne, T., Mitchell, S., and Bibb, R. "Design of human surrogates for the study of biomechanical injury: a review," Critical Reviews ${ }^{\mathrm{TM}}$ in Biomedical Engineering Vol. 41, No. 1, 2013.

Wang, Y., Tai, B. L., Yu, H., and Shih, A. J. "Silicone-Based Tissue-Mimicking Phantom for Needle Insertion Simulation," Journal of Medical Devices Vol. 8, No. 2, 2014, p. 021001.

Lualdi, M., Colombo, A., Farina, B., Tomatis, S., and Marchesini, R. "A phantom with tissue-like optical properties in the visible and near infrared for use in photomedicine," Lasers in surgery and medicine Vol. 28, No. 3, 2001, pp. 237243.

Madsen, E. L., and Frank, G. R. "Tissue mimicking elastography phantoms." Google Patents, 2008.

Kremer, M., Lang, E., and Berger, A. "Organotypical engineering of differentiated composite-skin equivalents of human keratinocytes in a collagen-GAG matrix (INTEGRA Artificial Skin) in a perfusion culture system," Langenbeck's Archives of Surgery Vol. 386, No. 5, 2001, pp. 357-363.

Payne, T., Mitchell, S., Bibb, R., and Waters, M. "Initial validation of a relaxed human soft tissue simulant for sports impact surrogates," Procedia engineering Vol. 72, 2014, pp. 533-538.

Payne, T., Mitchell, S., Bibb, R., and Waters, M. "The evaluation of new multi-material human soft tissue simulants for sports impact surrogates," Journal of the mechanical behavior of biomedical materials Vol. 41, 2015, pp. 336-356.

Bir, C. A., Resslar, M., and Stewart, S. "Skin penetration surrogate for the evaluation of less lethal kinetic energy munitions," Forensic science international Vol. 220, No. 1, 2012, pp. 126-129.

Jussila, J., Leppäniemi, A., Paronen, M., and Kulomäki, E. "Ballistic skin simulant," Forensic science international Vol. 150, No. 1, 2005, pp. 63-71.

Amick, D. "Gel compositions as muscle tissue simulant and related articles and methods." Google Patents, 2006. Giurintano, D., Callais, R., Cancienne, J. P., Lousteau, J., and Tumlin, J. "Torso simulator for ballistics testing." Google Patents, 2012.

Sudhoff, S. D., Glover, S. F., Lamm, P. T., Schmucker, D. H., and Delisle, D. "Admittance space stability analysis of power electronic systems," Aerospace and Electronic Systems, IEEE Transactions on Vol. 36, No. 3, 2000, pp. 965 973.

Schmidt, P. B. "An investigation of space suit mobility with applications to EVA operations." Massachusetts Institute of Technology, 2001. Oldham, S. "Less-Lethal Munitions," Law and Order Vol. 50, No. 2, 2002, pp. 54-56.

Arthur, B., and Janssen, P. A. "silicone breast implants," AWHONN Lifelines Vol. 4, No. 5, 2000, pp. 28-32.

Lapeer, R., Gasson, P., and Karri, V. "Simulating plastic surgery: From human skin tensile tests, through hyperelastic finite element models to real-time haptics," Progress in biophysics and molecular biology Vol. 103, No. 2, 2010, pp. 208-216.

Mahmud, J., Holt, C., Evans, S., Manan, N. F. A., and Chizari, M. "A parametric study and simulations in quantifying human skin hyperelastic parameters," Procedia Engineering Vol. 41, 2012, pp. 1580-1586.

Groves, R. B., Coulman, S. A., Birchall, J. C., and Evans, S. L. "An anisotropic, hyperelastic model for skin: experimental measurements, finite element modelling and identification of parameters for human and murine skin," Journal of the mechanical behavior of biomedical materials Vol. 18, 2013, pp. 167-180.

Gallagher, A., Ní Annaidh, A., and Bruyère, K. "Dynamic tensile properties of human skin," 2012 IRCOBI Conference Proceedings. International Research Council on the Biomechanics of Injury, 2012.

Martins, P., Natal Jorge, R., and Ferreira, A. "A Comparative Study of Several Material Models for Prediction of Hyperelastic Properties: Application to Silicone-Rubber and Soft Tissues," Strain Vol. 42, No. 3, 2006, pp. 135-147.

Shergold, O. A., Fleck, N. A., and Radford, D. "The uniaxial stress versus strain response of pig skin and silicone rubber at low and high strain rates," International Journal of Impact Engineering Vol. 32, No. 9, 2006, pp. 1384-1402.

Annaidh, A. N., Destrade, M., Ottenio, M., Bruyere, K., and Gilchrist, M. D. "Strain rate effects on the failure characteristics of excised human skin." 
Sasso, M., Palmieri, G., Chiappini, G., and Amodio, D. "Characterization of hyperelastic rubber-like materials by biaxial and uniaxial stretching tests based on optical methods," Polymer Testing Vol. 27, No. 8, 2008, pp. 995-1004.

Gonzalez, L. Y. S., Botero, M. G., and Betancur, M. "Hyperelastic Material Modeling," 2005.

Holzapfel, G. A. Nonlinear solid mechanics: Wiley Chichester, 2000. 